Article

\title{
Patterns of Occurrence and Outcomes of Contralateral Breast Cancer: Analysis of SEER Data
}

\author{
Zhenchong Xiong ${ }^{1,+} \mathbb{C}^{\mathbb{D}}$, Lin Yang ${ }^{2,+}$, Guangzheng Deng ${ }^{1,+}$, Xinjian Huang ${ }^{1}$, Xing Li $^{1}$, \\ Xinhua Xie ${ }^{1}$, Jin Wang ${ }^{1}$, Zeyu Shuang ${ }^{1}$ and Xi Wang ${ }^{1, *}$ \\ 1 Department of Breast Surgery, State Key Laboratory of Oncology in Southern China, Collaborative \\ Innovation Center for Cancer Medicine, Sun Yat-sen University Cancer Center, Guangzhou 510030, China; \\ xiongzhch@sysucc.org.cn (Z.X.); denggzh@sysucc.org.cn (G.D.); huangxj1@sysucc.org.cn (X.H.); \\ lixing@sysucc.org.cn (X.L.); xiexh@sysucc.org.cn (X.X.); wangjin1@sysucc.org.cn (J.W.); \\ shuangzy@sysucc.org.cn (Z.S.) \\ 2 State Key Laboratory of Oncology in Southern China, Collaborative Innovation Center for Cancer Medicine, \\ Sun Yat-sen University Cancer Center, Guangzhou 510030, China; yanglin@sysucc.org.cn \\ * Correspondence: wangxi@sysucc.org.cn; Tel.: +86-020-8734-3852 \\ + These authors contributed equally to this work and share the first authorship.
}

Received: 15 April 2018; Accepted: 28 May 2018; Published: 31 May 2018

\begin{abstract}
Population-based estimates are lacking for the temporal trends in the contralateral breast cancer $(\mathrm{CBC})$ risk for patients with breast cancer $(\mathrm{BC})$. Data for $\mathrm{BC}$ patients diagnosed with $\mathrm{CBC}$ were collected from the Surveillance, Epidemiology, and End Results database. CBC incidence was calculated using the Kaplan-Meier method and the temporal trend in CBC incidence was assessed using joinpoint regression. Survival analysis was calculated using propensity scoring (PS) and multivariate Cox regression with a competing risk model. We found that 10,944 of 212,630 patients with early-stage BC were subsequently diagnosed with secondary BC in the contralateral breast. The 5-, 10-, 15-, and 20-year cumulative CBC incidences were 1.9, 4.6, 7.6, and 10.5\%, respectively. Being younger ( $<40$ years), black, hormone receptor-negative, and having undergone radiotherapy were correlated with a high risk of $\mathrm{CBC}$ occurrence. $\mathrm{CBC}$ incidence increased continuously in the first 11 years after the initial cancer diagnosis, and the upward trend slowed from years 11 to 21, and tended to decline from years 21 to 24 . CBC diagnosis was significantly and negatively associated with survival. We reported population-based estimates of the $\mathrm{CBC}$ occurrence pattern and risk factors. Patients are at high risk of developing $\mathrm{CBC}$ in the first 21 years after the initial $\mathrm{BC}$ diagnosis.
\end{abstract}

Keywords: contralateral breast cancer; incidence; outcome; SEER; propensity score

\section{Introduction}

The incidence of contralateral breast cancer (CBC) is about $6.1 \% 10$ years after the initial diagnosis of breast cancer (BC) [1-3]. Although previous studies showed a favorable decrease in CBC incidence, improved survival, increased incidence, and decreased patient age have led to an increasing number of BC patients at risk of developing contralateral secondary BC $[1,2,4]$.Therefore, surveillance of metachronous $\mathrm{CBC}$ in patients with $\mathrm{BC}$ is important.

The risk of $\mathrm{BC}$ is higher in patients with $\mathrm{BC}$ compared to the risk in the general population, whereas the variation in the trend of $\mathrm{CBC}$ incidence, which is the change in $\mathrm{CBC}$ incidence per year during the follow-up in $\mathrm{BC}$ patients, has been seldom reported [5-7]. Moreover, initial cancer treatment may affect $\mathrm{CBC}$ risk, where endocrine treatment and chemotherapy can reduce $\mathrm{CBC}$ risk and delay CBC development [8-10]. This renders the occurrence pattern of $C B C$ unpredictable; therefore, optimal surveillance of $\mathrm{CBC}$ becomes challenging for cancer diagnoses. Another challenge faced by $\mathrm{CBC}$ 
surveillance is that the population of $B C$ patients with high $C B C$ risk is unknown, and studies on the risk factors of $C B C$ are limited. Patients with $B R C A 1$ or $B R C A 2$ gene mutation or with tumor history at a young age ( $<35$ years) have significantly higher $C B C$ risk, but represent only a small proportion of the $C B C$ population [11-13]. Identifying the patient and tumor characteristics corresponding to high $\mathrm{CBC}$ risk would be helpful for efficient surveillance of patients with $\mathrm{BC}$.

Previous studies reported that the early development of $C B C$ is associated with worse survival $[4,14]$. Post-therapy surveillance is of considerable value for $\mathrm{BC}$ patients to discover $\mathrm{CBC}$ in the early stages to improve survival. Thus, patients with $B C$ should receive periodic follow-up, including physical and imaging examination [15]. Studies of $\mathrm{CBC}$ occurrence regularity is important to guide the formulation of a surveillance plan for patients with BC.

In this study, we used the National Cancer Institute's Surveillance, Epidemiology, and End Results (SEER) database to estimate the CBC occurrence pattern in BC and to identify the population of BC patients who are susceptible to CBC. Moreover, we compared the overall survival (OS) and BC-specific survival of patients with $\mathrm{CBC}$ to that of patients with unilateral disease in early-stage BC.

\section{Experimental Section}

\subsection{Patients and Methods}

Patient information was collected from the SEER database, which includes nine registries [16]. We defined $B C$ with $T_{1-2}, N_{0-1}, M_{0}$ as early-stage $B C$, and included patients with no history of cancer who were diagnosed with BC between January 1990 and December 2009. CBC is defined as an invasive breast cancer diagnosed in the contralateral breast 2 months or more after the first diagnosis of invasive BC. Patients with local advanced or initial distant metastatic BC were not included, due to the poor survival of this group, as most of them may die of cancer progression before the CBC occurs. We excluded patients with: (1) diagnosis only on death certificate or autopsy; (2) follow-up <2 months; (3) unknown age or $<18$ years; (4) synchronous bilateral breast cancer; (5) or prophylactic removal of the contralateral breast, leaving 212,630 patients in the final study population. Among them, 10,944 patients were subsequently diagnosed with CBC. The follow-up period was from January 1990 to December 2013.

\subsection{Statistical Analysis}

We calculated the cumulative incidence of CBC using the Kaplan-Meier method [17]. CBC incidence was recorded per 1000 person-years. We then used joinpoint regression to analyze trends of $\mathrm{CBC}$ incidence and mortality risk. Joinpoint regression involves straight-line segment fitting to the cumulative incidence of $\mathrm{CBC}$, which are intersected at the joinpoint, where significant changes in trend occur. Rate changes were assessed using annual percent change (APC). Standardized incidence ratio (SIR), a ratio of observed to expected incidence based on the general population rates, was used to assess excess relative risk of $\mathrm{CBC}$ compared with the general population. Univariate and multivariate Cox regression models were used to identify CBC risk factors.

Overall survival (OS) was calculated from the date of the latest diagnosis of $\mathrm{BC}$ to the date of death. As our study was retrospective, selection bias may have occurred; therefore, multivariate analysis and the propensity score (PS) model were used to adjust for potential confounding factors from the following variables: age, Hispanic origin, race, sex, year of diagnosis, tumor grade, stage, hormone receptor status, surgery, and radiotherapy (Table S3). The PS was then used as an adjustment factor in the Cox regression models. Survival curves and multivariate Cox regression with a competing risk model were used to compare differences in OS- and BC-specific survival between patients with $\mathrm{CBC}$ and patients with unilateral BC. Additional subgroup survival analysis was performed based on stage.

All data were obtained using SEER $*$ Stat Software version 8.3.4 [18]. Statistical analysis was performed using Statistical analysis system (SAS) version 9.4. Joinpoint regression analysis was 
performed using Joinpoint software version 4.5.0.1 [19]. All $P$-values were two-sided; $P \leq 0.05$ was considered significant.

\section{Results}

\subsection{Occurrence Pattern of $C B C$ Incidence}

A total of 212,630 patients were diagnosed with early-stage BC, and 10,944 (5.1\%) developed CBC in 1990-2009. The 5-, 10-, 15-, and 20-year cumulative incidences of CBC were 1.9, 4.6, 7.6, and $10.5 \%$, respectively (Figure 1A). We examined the effect of patient and tumor characteristics on the risk of $\mathrm{CBC}$ by adjusting for the potential confounding factors (Table 1). Initial cancer diagnosis at a younger age ( $<40$ years), black ethnicity, receiving radiotherapy for the first $\mathrm{BC}$, and having hormone receptor-negative BC were significantly correlated with higher risk of CBC (Figure S1A-D and Table 1).

A

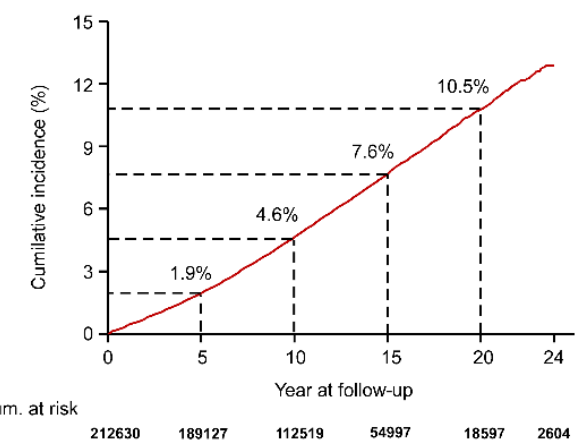

B

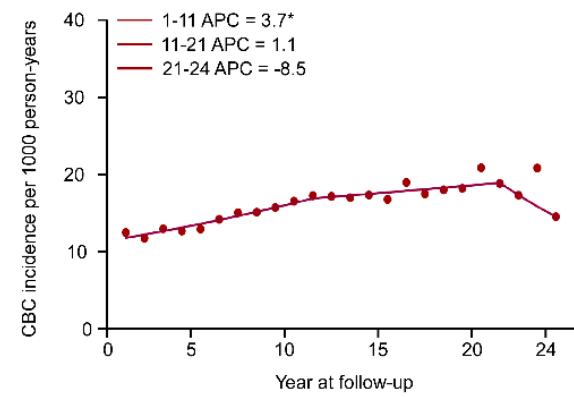

C

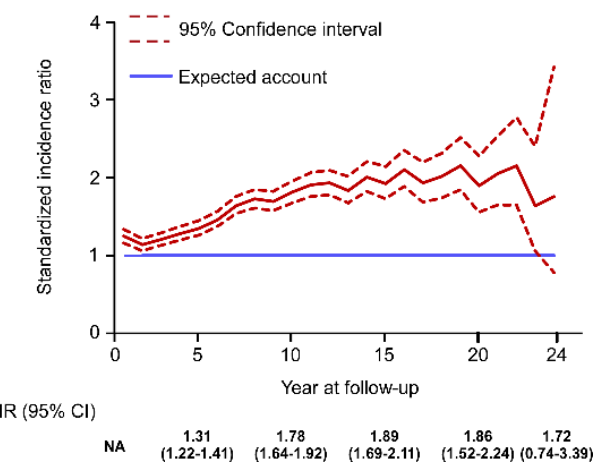

Figure 1. Temporal trend in contralateral breast cancer $(\mathrm{CBC})$ incidence over the 24-year follow-up period (1990-2013). (A) Cumulative incidence of CBC in early-stage breast cancer (BC). (B) Trend of CBC incidence per 1000 person-years estimated by joinpoint regression (Trend 1: years 1-11, Trend 2: years 11-21, Trend 3: years 21-24). (C) Trend in standardized incidence ratio (SIR) CBC in early-stage $\mathrm{BC}$ compared with the general population. ${ }^{*} P<0.05$. NA $=$ not available. 
Table 1. Univariate and multivariate Cox regression for the occurrence of contralateral breast cancer $(\mathrm{CBC})$ in early stage breast cancer (BC) patients.

\begin{tabular}{|c|c|c|c|c|c|c|}
\hline \multirow[b]{2}{*}{ Variable } & \multicolumn{3}{|c|}{ Univariate } & \multicolumn{3}{|c|}{ Multivariate $^{a}$} \\
\hline & HR & $95 \% \mathrm{CI}$ & $P$ Value & HR & $95 \%$ CI & $P$ Value \\
\hline \multicolumn{7}{|l|}{ Age } \\
\hline$<40$ & 1 & & & 1 & & \\
\hline $40-49$ & 0.708 & $0.656-0.763$ & $<0.001$ & 0.707 & $0.652-0.768$ & $<0.001$ \\
\hline 50-59 & 0.706 & $0.656-0.760$ & $<0.001$ & 0.709 & $0.654-0.768$ & $<0.001$ \\
\hline $60-69$ & 0.747 & $0.694-0.805$ & $<0.001$ & 0.759 & $0.700-0.824$ & $<0.001$ \\
\hline$\geq 70$ & 0.703 & $0.652-0.758$ & $<0.001$ & 0.746 & $0.686-0.811$ & $<0.001$ \\
\hline \multicolumn{7}{|l|}{ Race } \\
\hline Black & 1 & & & 1 & & \\
\hline White & 0.739 & $0.693-0.788$ & $<0.001$ & 0.762 & $0.709-0.819$ & $<0.001$ \\
\hline Other & 0.734 & $0.670-0.803$ & $<0.001$ & 0.744 & $0.674-0.822$ & $<0.001$ \\
\hline \multicolumn{7}{|l|}{ Year of diagnosis } \\
\hline 1990-1994 & 1 & & & 1 & & \\
\hline 1995-1999 & 1.062 & $1.011-1.115$ & 0.016 & 1.038 & 0.983-1.095 & 0.181 \\
\hline $2000-2004$ & 1.04 & $0.985-1.097$ & 0.158 & 0.994 & $0.937-1.055$ & 0.85 \\
\hline $2005-2009$ & 0.867 & $0.808-0.930$ & $<0.001$ & 0.837 & $0.775-0.903$ & $<0.001$ \\
\hline \multicolumn{7}{|l|}{ Stage } \\
\hline I & 1 & & & 1 & & \\
\hline IIA & 0.928 & $0.889-0.969$ & 0.01 & 0.91 & $0.868-0.954$ & $<0.001$ \\
\hline IIB & 0.935 & $0.872-1.002$ & 0.056 & 0.936 & $0.868-1.008$ & 0.079 \\
\hline \multicolumn{7}{|l|}{ Hormone receptor status } \\
\hline + vs. - & 0.814 & $0.775-0.855$ & $<0.001$ & 0.839 & $0.797-0.883$ & $<0.001$ \\
\hline \multicolumn{7}{|l|}{ Radiotherapy } \\
\hline Yes vs. No/Refused & 1.261 & $1.213-1.310$ & $<0.001$ & 1.258 & $1.206-1.312$ & $<0.001$ \\
\hline \multicolumn{7}{|l|}{ Sex } \\
\hline Male vs. Female & 0.332 & $0.209-0.526$ & $<0.001$ & 0.363 & $0.215-0.613$ & $<0.001$ \\
\hline
\end{tabular}

During the 24-year follow-up, the trend in CBC incidence had three phases (Figure 1B and Table 2). $\mathrm{CBC}$ incidence increased continuously in the first 11 years after the initial cancer diagnosis (Trend 1 , $\mathrm{APC}=3.7,95 \%$ confidence interval $(95 \% \mathrm{CI})=2.9-4.5)$. The upward trend slowed at year $11-21$ (Trend 2, $\mathrm{APC}=1.1 ; 95 \% \mathrm{CI}=-0.4$ to 2.7), and the incidence tended to decline at year 21-24 (Trend 3, $\mathrm{APC}=-8.5 ; 95 \% \mathrm{CI}=-24$ to 10.1). Subgroup analysis based on age showed that $\mathrm{CBC}$ incidence in younger patients increased more rapidly than in older patients (Figure S2A and Table 2). Among patients aged $\geq 70$ years, a significantly declining trend in CBC risk was observed between year 9 and 23 (Trend 2, APC $=-4.3,95 \% \mathrm{CI}=-8.2$ to -0.2 ; Figure S2A and Table 2). Regarding hormone receptor status, the increased trend in $\mathrm{CBC}$ in patients with initial hormone receptor-positive $\mathrm{BC}$ (Trend 1, $\mathrm{APC}=2.3,95 \% \mathrm{CI}=-7.2$ to 12.9 ; Trend $2, \mathrm{APC}=8.4,95 \% \mathrm{CI}=6.9-9.8$ ) was delayed compared with that in patients with initial hormone receptor-negative $\mathrm{BC}$ (Trend 1, APC $=44.1,95 \% \mathrm{CI}=7-94$; Trend 2, APC $=1.5,95 \% \mathrm{CI}=0.2-2.7$; Figure S2B and Table 2). Among patients who had undergone radiotherapy, the incidence of $\mathrm{CBC}$ increased continuously during follow-up, whereas no significant trend was observed in patients who had not undergone radiotherapy (Figure S2C and Table 2).

Furthermore, we assessed the temporal trend in excess risk of $\mathrm{BC}$ in $\mathrm{BC}$ patients compared to the risk in the general population. In the first 23 years of follow-up, the risk of secondary $B C$ in $B C$ patients was significantly higher than the risk of $B C$ in the general population. The 5-, 10-, 15-, and 20-year SIR (95\% CI) were 1.31 (1.22-1.41), 1.78 (1.64-1.92), 1.89 (1.69-2.11), and 1.86 (1.52-2.24), respectively (Figure 1C). At year 24, no significant excess morbidity risk was observed in the patients with BC (24-year SIR (95\% CI), 1.72 (0.74-3.39)). 
Table 2. Jointpoint regression for $\mathrm{CBC}$ incidence in patients with early stage BC.

\begin{tabular}{|c|c|c|c|c|c|c|}
\hline \multirow{3}{*}{ Characteristic } & \multicolumn{6}{|c|}{ Total } \\
\hline & \multicolumn{2}{|r|}{ Trend 1} & \multicolumn{2}{|r|}{ Trend 2} & \multicolumn{2}{|c|}{ Trend 3} \\
\hline & Period & APC $(95 \%$ CI $)$ & Period & APC $(95 \% \mathrm{CI})$ & Period & APC $(95 \% \mathrm{CI})$ \\
\hline \multicolumn{7}{|l|}{ Age } \\
\hline$<40$ & $1-4$ & $51.4^{*},(12.8-103.1)$ & $4-24$ & $0.6,((-1.6)-3.0)$ & NA & NA \\
\hline $60-69$ & $1-11$ & $6.4 *,(4.8-8.0)$ & $11-23$ & $-0.2,((-2.6)-2.4)$ & NA & NA \\
\hline$\geq 70$ & $1-9$ & $5.7 *,(3.0-8.5)$ & $9-23$ & $-4.3^{*},((-8.2)-(-0.2))$ & NA & NA \\
\hline \multicolumn{7}{|l|}{ Race } \\
\hline Black & $1-7$ & $17.7 *,(11.1-24.6)$ & $7-23$ & $-0.5,((-3.0)-2.1)$ & NA & NA \\
\hline White & $1-10$ & $7.1 *,(6.2-7.9)$ & $10-24$ & $1.0 *,(0.1-2.0)$ & NA & NA \\
\hline Other & $1-24$ & $6.6^{*},(5.2-8.0)$ & NA & NA & NA & NA \\
\hline 2000-2004 & $1-14$ & $6.7^{*},(5.5-8.0)$ & NA & NA & NA & NA \\
\hline 2005-2009 & $1-3$ & $-16.5,((-43.4)-23.1)$ & $3-9$ & $21.0 *,(10.3-32.7)$ & NA & NA \\
\hline \multicolumn{7}{|l|}{ Stage } \\
\hline I & $1-8$ & $8.8 *,(7.6-10.0)$ & $8-19$ & $2.1 *,(1.2-3.0)$ & $19-24$ & $-5.6 *,((-13.6)-3.2)$ \\
\hline IIA & $1-10$ & $7.0 *,(5.2-8.9)$ & $10-24$ & $1.4,((-0.6)-3.4)$ & NA & NA \\
\hline IIB & $1-23$ & $5.4 *,(4.2-6.6)$ & NA & NA & NA & NA \\
\hline \multicolumn{7}{|c|}{ Hormone receptor status } \\
\hline+ & $1-3$ & $2.3,((-7.2)-12.9)$ & $3-11$ & $8.4^{*},(6.9-9.8)$ & $11-24$ & $0.8,((-0.4)-2.1)$ \\
\hline- & $1-3$ & $44.1^{*},(7.0-94.0)$ & $3-24$ & $1.5 *,(0.2-2.7)$ & NA & NA \\
\hline \multicolumn{7}{|l|}{ RT } \\
\hline
\end{tabular}

\subsection{Overall and Cancer-Specific Survival}

The outcomes of patients with secondary $\mathrm{BC}$ are seldom reported. In patients with $\mathrm{CBC}$ and patients with unilateral $\mathrm{BC}, \mathrm{BC}$ caused $36.1 \%$ and $27.9 \%$ of deaths, respectively (Table S2). Survival analysis was performed on patients with $C B C$ and patients with unilateral BC. Both the multivariate-adjusted and PS-adjusted models showed that patients with $\mathrm{CBC}$ had significantly shorter OS than those with unilateral BC (unilateral BC vs. $C B C$ hazard ratio $(H R)=0.776,95 \% C I=0.743-0.810$; $\mathrm{HR}=0.815,95 \% \mathrm{CI}=0.780-0.852$ for multivariate-adjusted and PS-adjusted, respectively; Figure 2A and Table 3). Subgroup survival analysis based on stage showed that patients with unilateral $B C$ had better OS compared with the patients with CBC (Figure 2B-D and Table 3).

Although patients with $\mathrm{CBC}$ had worse OS, only a small proportion died due to $\mathrm{BC}$. Accordingly, we analyzed BC-specific survival using a competing risk model. In patients with stage IIB CBC, $62.6 \%$ of patient deaths were due to $B C$, whereas $48.2 \%$ and $28.6 \%$ of deaths were $B C$-related in patients with stage IIA and stage I CBC, respectively (Table S2). In the entire cohort, patients with unilateral $\mathrm{BC}$ had 0.51 times lower $\mathrm{BC}$-specific risk of mortality than patients with $\mathrm{CBC}$ (unilateral $\mathrm{BC}$ vs. $\mathrm{CBC}$, $\mathrm{HR}=0.482,95 \% \mathrm{CI}=0.447-0.520 ; \mathrm{HR}=0.51,95 \% \mathrm{CI}=0.474-0.549$ for multivariate-adjusted and PS-adjusted, respectively; Figure 2E and Table 3). Moreover, CBC was correlated with worse BC-specific survival regardless of tumor stage (Figure $2 \mathrm{~F}-\mathrm{H}$ and Table 3 ). 
A

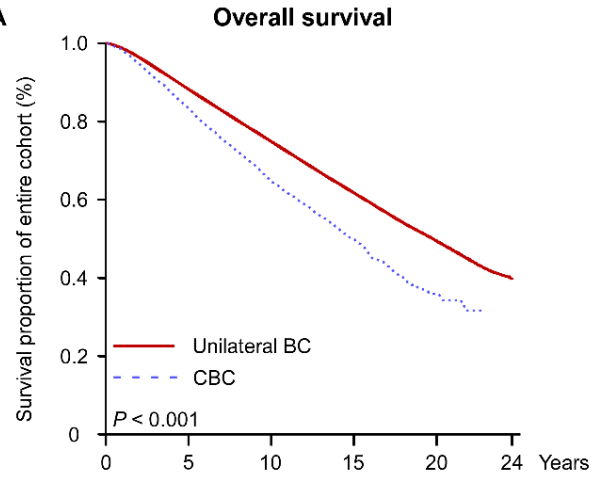

B

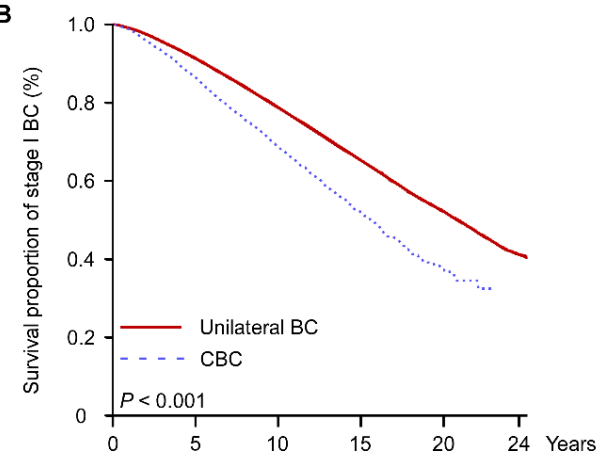

c

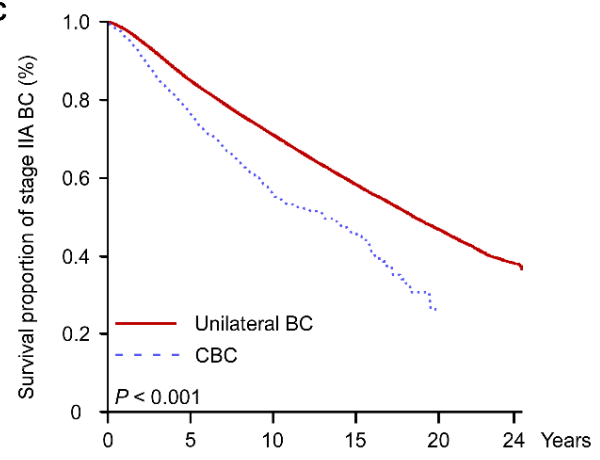

D

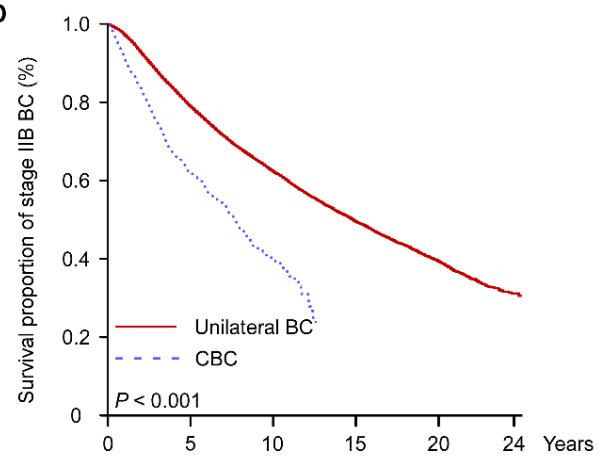

E

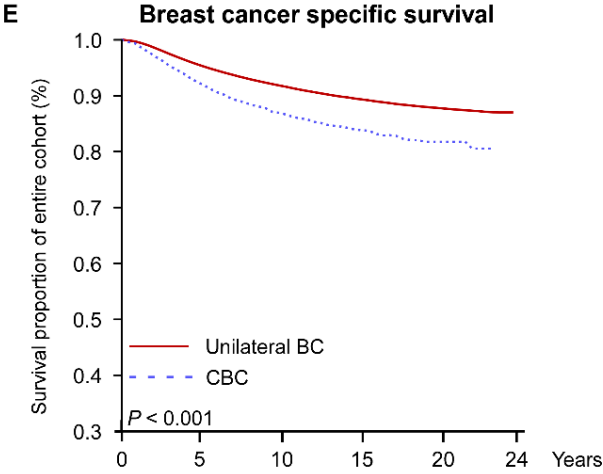

$\mathbf{F}$

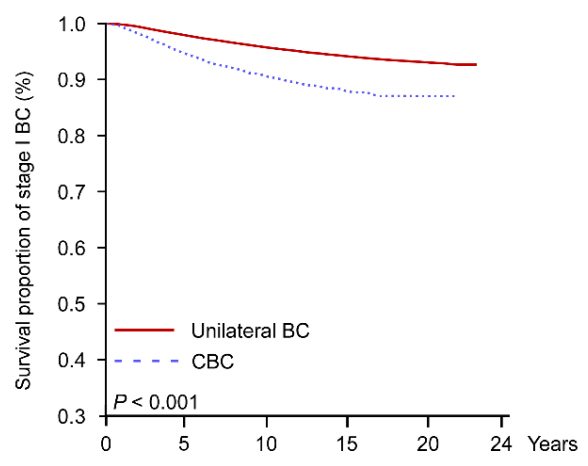

G

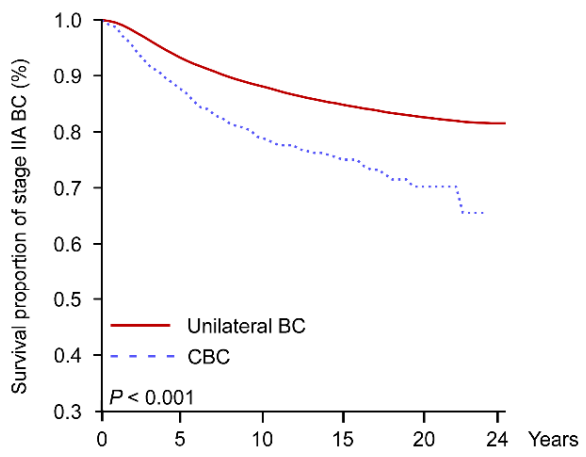

H

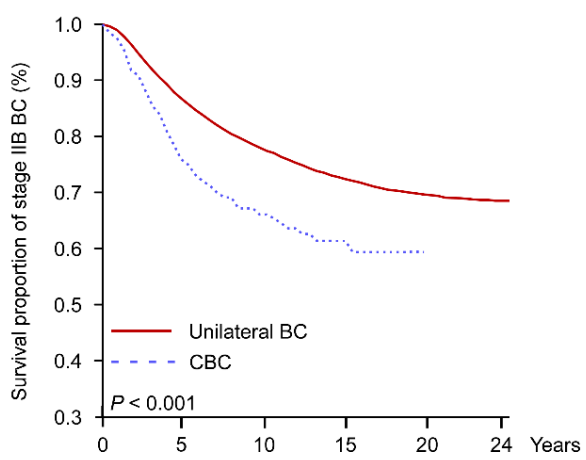

Figure 2. Overall and BC-specific survival analyses adjusted using the propensity scoring (PS) model between patients with early-stage unilateral $\mathrm{BC}$ and patients with early-stage $\mathrm{CBC}$. All values are based on the PS model. Left - overall survival (OS): (A) entire cohort, (B) stage I, (C) stage IIA, and (D) stage IIB. Right-BC-specific survival: (E) entire cohort, (F) stage I, (G) stage IIA, and (H) stage IIB. $\mathrm{BC}=$ breast cancer; $\mathrm{CBC}=$ contralateral breast cancer. 
Table 3. Subgroup analysis of overall and breast cancer-specific survival (unilateral vs. contralateral BC) based on stage (I, IIA, and IIB).

\begin{tabular}{|c|c|c|c|c|c|c|}
\hline \multirow{2}{*}{ Stage } & \multicolumn{2}{|c|}{ Unadjusted $^{a}$} & \multicolumn{2}{|c|}{ Multivariate-Adjusted $^{a, b}$} & \multicolumn{2}{|c|}{ PS-Adjusted ${ }^{a, b}$} \\
\hline & HR $(95 \% \mathrm{CI})$ & $P$ Value & HR $(95 \% \mathrm{CI})$ & $P$ Value & HR $(95 \% \mathrm{CI})$ & $P$ Value \\
\hline \multicolumn{7}{|c|}{ Overall survival } \\
\hline All & $0.676(0.648-0.706)$ & $<0.001$ & $0.776(0.743-0.810)$ & $<0.001$ & $0.815(0.780-0.852)$ & $<0.001$ \\
\hline I & $0.638(0.606-0.673)$ & $<0.001$ & $0.777(0.737-0.820)$ & $<0.001$ & $0.825(0.782-0.870)$ & $<0.001$ \\
\hline IIA & $0.627(0.575-0.684)$ & $<0.001$ & $0.754(0.691-0.823)$ & $<0.001$ & $0.790(0.724-0.863)$ & $<0.001$ \\
\hline IIB & $0.604(0.520-0.702)$ & $<0.001$ & $0.750(0.645-0.873)$ & $<0.001$ & $0.716(0.616-0.833)$ & $<0.001$ \\
\hline \multicolumn{7}{|c|}{ Breast cancer-specific survival } \\
\hline All & $0.630(0.586-0.678)$ & $<0.001$ & $0.482(0.447-0.520)$ & $<0.001$ & $0.510(0.474-0.549)$ & $<0.001$ \\
\hline I & $0.457(0.414-0.505)$ & $<0.001$ & $0.427(0.385-0.474)$ & $<0.001$ & $0.445(0.402-0.494)$ & $<0.001$ \\
\hline IIA & $0.559(0.492-0.634)$ & $<0.001$ & $0.521(0.458-0.594)$ & $<0.001$ & $0.552(0.486-0.627)$ & $<0.001$ \\
\hline IIB & $0.609(0.502-0.740)$ & $<0.001$ & $0.572(0.467-0.701)$ & $<0.001$ & $0.594(0.488-0.723)$ & $<0.001$ \\
\hline
\end{tabular}

a 4,786 patients with CBC were excluded in the survival analysis due to: (1) diagnosis of stage III, IV, or unknown stage and (2) time of diagnosis between 2010-2013. ${ }^{\mathrm{b}}$ Co-variates for multivariate and PS-adjustment: age, Hispanic origin, race, sex, marital status, year of diagnosis, tumor grade, stage, hormone receptor status, surgery, and RT. $\mathrm{BC}=$ breast cancer; $\mathrm{CBC}=$ contralateral breast cancer; $\mathrm{RT}=$ radiotherapy; $\mathrm{PS}=$ propensity score; $\mathrm{HR}=$ odds ratio; $95 \% \mathrm{CI}=95 \%$ confidence interval.

\section{Discussion}

First, our study revealed the temporal trend in $\mathrm{CBC}$ incidence and identified the risk factors of $C B C$ in patients with $B C$. Further, we compared the outcomes of patients with $C B C$ with those of patients with unilateral $B C$, and found that the diagnosis of $C B C$ adversely affected survival in early-stage BC.

The risk of $C B C$ is greater in patients with $B C$ than the risk of $B C$ in the general population [20]. As cancer mortality is decreasing and life expectancy is increasing, patients with $\mathrm{BC}$, especially those with early-stage BC, have an increased probability of developing secondary BC. In our study, we excluded patients with poor prognosis and short survival, including patients with local advanced or initial stage IV BC, to avoid underestimating the $\mathrm{CBC}$ incidence. We found that patients with $\mathrm{BC}$ have a significantly higher risk of $\mathrm{CBC}$ than the general population's risk of $\mathrm{BC}$, and that the excess risk remains significant until 23 years after the initial diagnosis of $B C$. Therefore, the purpose of surveilling patients with $\mathrm{BC}$ is not only to detect cancer recurrence but also to discover $\mathrm{CBC}$ development. Presently, most patients undergo physical and imaging examination one to four times per year for the first five years, and then once annually [21]. Patients should be more vigilant about examinations for $\mathrm{CBC}$ when $\mathrm{CBC}$ incidence is high, whereas excessive imaging would only increase medical costs and does not aid in the early detection of $\mathrm{CBC}$. Studies on the variation trend of $\mathrm{CBC}$ incidence are needed to guide the management of cancer surveillance. We observed that $\mathrm{CBC}$ incidence increased continuously within the 11 years after the first diagnosis of $B C$, and remained at a peak in years 11 to 21 . These results suggest that patients with $B C$ have a high risk of $C B C$ for over 21 years; therefore, they should attach great importance to the occurrence of $C B C$.

$\mathrm{CBC}$ incidence varies from person to person, and identifying the high-risk population for $\mathrm{CBC}$ is important for optimal surveillance and management of patients with $B C$. The risk of $C B C$ decreases with increased age at initial diagnosis of $B C[22,23]$. Compared with older patients, younger patients tend to have unfavorable genetic profiles (including BRCA1 and BRCA2 mutation), which may contribute to a high risk of $B C$ [24-26]. Consistently, we found that younger patients with $B C$ ( $<40$ years) had significantly higher $C B C$ risk than older patients. Moreover, we found that younger patients reached peak $C B C$ morbidity earlier and that the peak lasted longer compared with older patients. As patients with cancer diagnosis at a younger age have a longer life expectancy than the older patients, shorter intervals between examination and a prolonged period of close follow-up should be considered. In addition, hormone receptor status was significantly correlated with risk of CBC [5,27]. In our study, patients with hormone receptor-negative $\mathrm{BC}$ were more susceptible to $\mathrm{CBC}$. We assumed that the 
lower $\mathrm{CBC}$ risk was attributed to the wide use of endocrine treatment in hormone receptor-positive $\mathrm{BC}$. Given the effectiveness of endocrine treatment, including aromatase inhibitors and tamoxifen, in $\mathrm{BC}$ prevention, most patients with hormone receptor-positive $B C$ would undergo endocrine treatment in the first five years to prevent cancer recurrence, which simultaneously lowers their risk of CBC [28-30]. Conversely, patients with hormone receptor-negative $\mathrm{BC}$ respond poorly to endocrine treatment, so that most refuse endocrine treatment and are more likely to develop CBC. Interestingly, we observed that the risk of $C B C$ in hormone receptor-positive $B C$ temporarily decreased in the first five years, and increased rapidly thereafter. These results indicate that the protective effect of endocrine treatment against $\mathrm{CBC}$ is transitory and that patients who undergo endocrine therapy should remain vigilant upon completing endocrine treatment. As the duration of endocrine treatment has been extended to 10 years, whether the extended endocrine treatment can further delay $\mathrm{CBC}$ development in patients with hormone receptor-positive BC should be studied further $[29,31]$. Future studies on CBC risk should assess the protective effect of endocrine treatment between patients with five-year regimens and those with 10-year regimens.

In our study, we discovered that patients with CBC had significantly worse survival compared to patients with unilateral disease in early-stage BC. These findings are consistent with the previous studies that patients who developed $C B C$ early, in the first five years after the initial diagnosis of $B C$, have excess mortality risk compared to patients with unilateral $B C[2,4,14]$. At present, no evidence exists that correlates $C B C$ with more aggressive biological behavior compared to the first $B C$, and we found that the higher risk of mortality remained significant in different BC stages (stages I, IIA, and IIIB). Therefore, we assume that the poor prognosis in patients with $\mathrm{CBC}$ might be attributed to the influence of cancer treatment. Drug resistance induced by prior therapy and cumulative toxicity caused by chemotherapy may be reasons for the excess mortality risk in $\mathrm{CBC}$, and over-dosage of radiation to normal organs caused by a second regimen of radiotherapy might also increase the risk of mortality. Although the reason patients with CBC have a worse outcome is unknown, our results indicate that $C B C$ diagnosis is correlated with poor prognosis and that reducing $C B C$ occurrence definitively improves $B C$ survival. Patients with a high risk of $C B C$ may consider prophylactic resection of the contralateral breast for preventing CBC.

Our study was based on SEER data, comprising patient information collected from nine registries from 1990 to 2009 in the United States. Therefore, the variation trend in CBC incidence we report is highly representative of the general population. However, our study has limitations. As this is a retrospective study, missing data and selection bias are inevitable. Thus, we used the PS model to adjust selection bias from tumor- and patient-specific variables. The details of systematic therapy, including endocrine treatment and chemotherapy, were not available, and the relevant biases may exist.

\section{Conclusions}

In conclusion, our results showed that $\mathrm{CBC}$ incidence increased continuously in the first 11 years after the initial cancer diagnosis, and the upward trend slowed during years 11 to 21 , and tended to decline at years 21 to 24 . Furthermore, the diagnosis of $C B C$ is correlated with poor prognosis regardless of tumor stage in early-stage $\mathrm{BC}$. Consequently, patients should accept intensive surveillance for 20 or more years after the initial diagnosis of BC.

Supplementary Materials: The following are available online at http://www.mdpi.com/2077-0383/7/6/133/s1, Figure S1. Estimates of CBC incidence among subgroups: (A) age, (B) race, (C) radiotherapy, and (D) hormone receptor status. RT = radiotherapy; Figure S2. Trends in CBC incidence per 1000 person-years estimated by joinpoint regression among subgroups: (A) age, (B) hormone receptor status, and (C) radiotherapy. $C B C=$ contralateral breast cancer, RT $+=$ underwent radiotherapy, and RT $-=$ did not undergo radiotherapy; Table S1: Characteristics of patients with unilateral or contralateral breast cancer; Table S2: Cause of death among patients with unilateral BC or CBC; Table S3: Comparison of characteristics between patients with unilateral BC and CBC, chi-square test.

Author Contributions: Z.X. Conceptualization, formal analysis, software, and writing-review and editing. L.Y. and J.W. Formal analysis, software, and writing-review and editing. G.D. Conceptualization, formal 
analysis, software. X.H. Data curation, methodology. X.L. formal analysis, writing-original draft. X.X. software, writing-original draft. Z.S. Data curation, methodology. X.W. Conceptualization, project administration and writing-review and editing.

Acknowledgments: This research did not receive any grant from funding agencies in the public, commercial, or not-for-profit sectors.

Conflicts of Interest: All authors declare that they have no conflicts of interest.

\section{References}

1. Lehman, C.D.; Gatsonis, C.; Kuhl, C.K.; Hendrick, R.E.; Pisano, E.D.; Hanna, L.; Peacock, S.; Smazal, S.F.; Maki, D.D.; Julian, T.B.; et al. MRI evaluation of the contralateral breast in women with recently diagnosed breast cancer. N. Engl. J. Med. 2007, 356, 1295-1303. [CrossRef] [PubMed]

2. Heron, D.E.; Komarnicky, L.T.; Hyslop, T.; Schwartz, G.F.; Mansfield, C.M. Bilateral breast carcinoma: Risk factors and outcomes for patients with synchronous and metachronous disease. Cancer 2000, 88, 2739-2750. [CrossRef]

3. Nichols, H.B.; Berrington de Gonzalez, A.; Lacey, J.V., Jr.; Rosenberg, P.S.; Anderson, W.F. Declining incidence of contralateral breast cancer in the United States from 1975 to 2006. J. Clin. Oncol. 2011, 29, 1564-1569. [CrossRef] [PubMed]

4. Hartman, M.; Czene, K.; Reilly, M.; Adolfsson, J.; Bergh, J.; Adami, H.O.; Dickman, P.W.; Hall, P. Incidence and prognosis of synchronous and metachronous bilateral breast cancer. J. Clin. Oncol. 2007, 25, 4210-4216. [CrossRef] [PubMed]

5. Rusner, C.; Wolf, K.; Bandemer-Greulich, U.; Engel, J.; Stegmaier, C.; Holleczek, B.; Schubert-Fritschle, G.; Tillack, A.; Stang, A. Risk of contralateral second primary breast cancer according to hormone receptor status in Germany. Breast Cancer Res. 2014, 16, 452. [CrossRef] [PubMed]

6. Knight, J.A.; Fan, J.; Malone, K.E.; John, E.M.; Lynch, C.F.; Langballe, R.; Bernstein, L.; Shore, R.E.; Brooks, J.D.; Reiner, A.S.; et al. Alcohol consumption and cigarette smoking in combination: A predictor of contralateral breast cancer risk in the WECARE study. Int. J. Cancer 2017, 141, 916-924. [CrossRef] [PubMed]

7. Reiner, A.S.; Lynch, C.F.; Sisti, J.S.; John, E.M.; Brooks, J.D.; Bernstein, L.; Knight, J.A.; Hsu, L.; Concannon, P.; Mellemkjaer, L.; et al. Hormone receptor status of a first primary breast cancer predicts contralateral breast cancer risk in the WECARE study population. Breast Cancer Res. 2017, 19, 83. [CrossRef] [PubMed]

8. Bertelsen, L.; Bernstein, L.; Olsen, J.H.; Mellemkjaer, L.; Haile, R.W.; Lynch, C.F.; Malone, K.E.; Anton-Culver, H.; Christensen, J.; Langholz, B.; et al. Effect of systemic adjuvant treatment on risk for contralateral breast cancer in the Women's Environment, Cancer and Radiation Epidemiology Study. J. Nat. Cancer Inst. 2008, 100, 32-40. [CrossRef] [PubMed]

9. Langballe, R.; Mellemkjaer, L.; Malone, K.E.; Lynch, C.F.; John, E.M.; Knight, J.A.; Bernstein, L.; Brooks, J.; Andersson, M.; Reiner, A.S.; et al. Systemic therapy for breast cancer and risk of subsequent contralateral breast cancer in the WECARE Study. Breast Cancer Res. 2016, 18, 65. [CrossRef] [PubMed]

10. Gierach, G.L.; Curtis, R.E.; Pfeiffer, R.M. Association of adjuvant tamoxifen and aromatase inhibitor therapy with contralateral breast cancer risk among us women with breast cancer in a general community setting. JAMA Oncol. 2017, 3, 186-193. [CrossRef] [PubMed]

11. Gronwald, J.; Robidoux, A.; Kim-Sing, C.; Tung, N.; Lynch, H.T.; Foulkes, W.D.; Manoukian, S.; Ainsworth, P.; Neuhausen, S.L.; Demsky, R.; et al. Duration of tamoxifen use and the risk of contralateral breast cancer in BRCA1 and BRCA2 mutation carriers. Breast Cancer Res. Treat 2014, 146, 421-427. [CrossRef] [PubMed]

12. Narod, S.A.; Brunet, J.S.; Ghadirian, P.; Robson, M.; Heimdal, K.; Neuhausen, S.L.; Stoppa-Lyonnet, D.; Lerman, C.; Pasini, B.; de los Rios, P.; et al. Tamoxifen and risk of contralateral breast cancer in BRCA1 and BRCA2 mutation carriers: A case-control study. Hereditary Breast Cancer Clinical Study Group. Lancet 2000, 356, 1876-1881. [CrossRef]

13. Rosenberg, S.M.; Ruddy, K.J.; Tamimi, R.M.; Gelber, S.; Schapira, L.; Come, S.; Borges, V.F.; Larsen, B.; Garber, J.E.; Partridge, A.H. BRCA1 and BRCA2 Mutation Testing in Young Women With Breast Cancer. JAMA Oncol. 2016, 2, 730-736. [CrossRef] [PubMed]

14. Liederbach, E.; Wang, C.H.; Lutfi, W.; Kantor, O.; Pesce, C.; Winchester, D.J.; Yao, K. Survival Outcomes and Pathologic Features Among Breast Cancer Patients Who Have Developed a Contralateral Breast Cancer. Ann. Surg. Oncol. 2015, 22 (Suppl. 3), S412-S421. [CrossRef] [PubMed] 
15. NCCN Clinical Practice Guidelines in Oncology-Breast Cancer (Version 1.2018). Available online: https: / / www.nccn.org / professionals / physician_gls / pdf/breast.pdf\#page=2\&zoom=auto,-247,476 (accessed on 20 March 2018).

16. Surveillance, E.; Results, E. (SEER) Program Research Data (1973-2013), National Cancer Institute, DCCPS, Surveillance Research Program, Surveillance Systems Branch, Released April 2016, Based on the November 2015 Submission. Available online: http:/ / www.seer.cancer.gov (accessed on 15 August 2016).

17. Li, G.; Zhang, P.; Wang, J.; An, Y.; Gong, Q.; Gregg, E.W.; Yang, W.; Zhang, B.; Shuai, Y.; Hong, J.; et al. Cardiovascular mortality, all-cause mortality, and diabetes incidence after lifestyle intervention for people with impaired glucose tolerance in the Da Qing Diabetes Prevention Study: A 23-year follow-up study. Lancet Diabetes Endocrinol. 2014, 2, 474-480. [CrossRef]

18. SEER ${ }^{*}$ Stat Software. Available online: https://seer.cancer.gov/seerstat/ (accessed on 29 May 2018).

19. Joinpoint Regression Program, Version 4.5.0.1. Statistical Research and Applications Branch, National Cancer Institute. Available online: https:/ / surveillance.cancer.gov/joinpoint/download (accessed on 12 June 2017).

20. Chen, Y.; Thompson, W.; Semenciw, R.; Mao, Y. Epidemiology of contralateral breast cancer. Cancer Epidemiol. Biomark. Prev. 1999, 8, 855-861.

21. Runowicz, C.D.; Leach, C.R.; Henry, N.L.; Henry, K.S.; Mackey, H.T.; Cowens-Alvarado, R.L.; Cannady, R.S.; Pratt-Chapman, M.L.; Edge, S.B.; Jacobs, L.A.; et al. American Cancer Society/ American Society of Clinical Oncology Breast Cancer Survivorship Care Guideline. Cancer J. Clin. 2016, 66, 43-73. [CrossRef] [PubMed]

22. Van der Hage, J.A.; Mieog, J.S.; van de Velde, C.J.; Putter, H.; Bartelink, H.; van de Vijver, M.J. Impact of established prognostic factors and molecular subtype in very young breast cancer patients: Pooled analysis of four EORTC randomized controlled trials. Breast Cancer Res. 2011, 13, R68. [CrossRef] [PubMed]

23. Arrington, A.K.; Voci, A.; Reparaz, L.; Fry, W. Factors and outcomes associated with surgical treatment options of contralateral breast cancer. Am J. Surg. 2014, 208, 524-530. [CrossRef] [PubMed]

24. Rosenberg, S.M.; Sepucha, K.; Ruddy, K.J.; Tamimi, R.M.; Gelber, S.; Meyer, M.E.; Schapira, L.; Come, S.E.; Borges, V.F.; Golshan, M.; et al. Local Therapy Decision-Making and Contralateral Prophylactic Mastectomy in Young Women with Early-Stage Breast Cancer. Ann. Surg. Oncol. 2015, 22, 3809-3815. [CrossRef] [PubMed]

25. Metcalfe, K.; Gershman, S.; Lynch, H.T.; Ghadirian, P.; Tung, N.; Kim-Sing, C.; Olopade, O.I.; Domchek, S.; McLennan, J.; Eisen, A.; et al. Predictors of contralateral breast cancer in BRCA1 and BRCA2 mutation carriers. Br. J. Cancer 2011, 104, 1384-1392. [CrossRef] [PubMed]

26. Kuchenbaecker, K.B.; Hopper, J.L.; Barnes, D.R.; Phillips, K.A.; Mooij, T.M.; Roos-Blom, M.J.; Jervis, S.; van Leeuwen, F.E.; Milne, R.L.; Andrieu, N.; et al. Risks of Breast, Ovarian, and Contralateral Breast Cancer for BRCA1 and BRCA2 Mutation Carriers. Jama 2017, 317, 2402-2416. [CrossRef] [PubMed]

27. Kurian, A.W.; McClure, L.A.; John, E.M.; Horn-Ross, P.L.; Ford, J.M.; Clarke, C.A. Second primary breast cancer occurrence according to hormone receptor status. J. Nat. Cancer Inst. 2009, 101, 1058-1065. [CrossRef] [PubMed]

28. Coombes, R.C.; Hall, E.; Gibson, L.J.; Paridaens, R.; Jassem, J.; Delozier, T.; Jones, S.E.; Alvarez, I.; Bertelli, G.; Ortmann, O.; et al. A randomized trial of exemestane after two to three years of tamoxifen therapy in postmenopausal women with primary breast cancer. N. Engl. J. Med. 2004, 350, 1081-1092. [CrossRef] [PubMed]

29. Forbes, J.F.; Sestak, I.; Howell, A.; Bonanni, B.; Bundred, N.; Levy, C.; von Minckwitz, G.; Eiermann, W.; Neven, P.; Stierer, M.; et al. Anastrozole versus tamoxifen for the prevention of locoregional and contralateral breast cancer in postmenopausal women with locally excised ductal carcinoma in situ (IBIS-II DCIS): A double-blind, randomised controlled trial. Lancet 2016, 387, 866-873. [CrossRef]

30. Li, C.I.; Daling, J.R.; Porter, P.L.; Tang, M.T.; Malone, K.E. Adjuvant hormonal therapy for breast cancer and risk of hormone receptor-specific subtypes of contralateral breast cancer. Cancer Res. 2009, 69, 6865-6870. [CrossRef] [PubMed]

31. Goss, P.E.; Ingle, J.N.; Pritchard, K.I.; Robert, N.J.; Muss, H.; Gralow, J.; Gelmon, K.; Whelan, T.; Strasser-Weippl, K.; Rubin, S.; et al. Extending Aromatase-Inhibitor Adjuvant Therapy to 10 Years. N. Engl. J. Med. 2016, 375, $209-219$. [CrossRef] [PubMed]

(C) 2018 by the authors. Licensee MDPI, Basel, Switzerland. This article is an open access article distributed under the terms and conditions of the Creative Commons Attribution (CC BY) license (http://creativecommons.org/licenses/by/4.0/). 